\title{
Microestrutura e Resistência à Fadiga de Um Aço Inoxidável Martensítico Macio Refundido Por Tocha Plasma
}

(Microstructure and Fatigue Strength in a Low Carbon Martensitic Stainless Steel Remelted by Plasma Torch)

\author{
Sérgio L. Henke, Matheus Müller, Edson H. Takano, Ramón S. C. Paredes \\ Universidade Federal do Paraná Departamento de Engenharia Mecânica - Curitiba, PR, Brasil. \\ henke@ufpr.br Centro Politécnico CxP 19011,81531-990 Curitiba PR, Brasil - Fone (041) 3361-3443
}

Resumo

Este trabalho teve como objetivo avaliar o efeito produzido pela refusão superficial por meio de uma tocha plasma na resistência à fadiga de um aço inoxidável martensítico macio utilizado na fabricação de rotores de turbinas hidráulicas. As refusões foram efetuadas na superfície deste tipo de aço utilizando corrente contínua e pulsada sendo os ensaios de fadiga realizados por meio de flexão em quatro pontos nas tensões de 750, 850 e $1000 \mathrm{MPa}$. Foi constatado um melhor desempenho da condição refundida em relação ao material sem este tratamento. Não foram constatadas diferenças significativas de desempenho à fadiga para as refusões utilizando corrente contínua e convencional. A presença de tensões residuais compressivas decorrentes da transformação martensítica em parte justifica o melhor desempenho da condição refundida. Análises microscópicas complementares revelaram que o menor desempenho à fadiga do material base sem refusão estava associado também à presença de defeitos (microrechupes) provenientes do processo de fundição os quais promoviam à nucleação de trincas de fadiga junto aos mesmos. A presença de ferrita delta, situada junto às ripas de martensita orientadas a $45^{\circ} \mathrm{em}$ relação à direção de carregamento, promoveu a nucleação das trincas de fadiga nos corpos de prova com tratamento de refusão superficial.

Palavras-chave: Aço inoxidável martensítico. Soldagem plasma; Fadiga; Ferrita delta.

\begin{abstract}
This study aimed to evaluate the effect of surface remelting by a plasma torch on fatigue resistance of a soft martensitic stainless steel used in the manufacture of hydraulic turbine rotors. The remelting was performed on the surface of this type of steel using direct and pulsed current with the fatigue tests performed by bending at four points at 750, 850 and $1000 \mathrm{MPa}$ stresses. It was found better performance of the remelted condition in relation to cast material without this treatment and no significant differences in fatigue performance between the two remelted processes. The presence of compressive residual stresses resulting from the martensitic transformation partly explains the better performance of the remelted condition. Microscopic analysis further revealed that the lower the fatigue performance of the base material was also associated with the presence of defects (microshrinkage) from the casting process which promoted the nucleation of fatigue cracks next to them. The presence of delta ferrite together with martensite laths oriented at $45^{\circ}$ to the loading direction, promoted fatigue cracks nucleation in specimens with surface remelted treatment.
\end{abstract}

Key-words: Martensitic stainless steel; Plasma welding; Fatigue; Delta-ferrite.

\section{Introdução}

A falha de componentes de engenharia é quase sempre um evento indesejável por diversos motivos que incluem vidas humanas colocadas em risco, perdas econômicas e a interferência com a disponibilidade de produtos e serviços. Dentre os diferentes modos de falha, a falha por fadiga representa aproximadamente entre 50 a $90 \%$ de todas as falhas dos materiais metálicos [1].

Melhorar a resistência à fadiga dos componentes, em grande parte das vezes, envolve a realização de tratamentos superficiais os quais resultem num aumento da resistência e também na criação de tensões residuais de compressão nesta região [2]. Uma forma de obtenção envolve a realização da fusão superficial onde por

Recebido em 17/03/2014, texto final em 07/04/2014. meio de transformações, seja esta durante a solidificação (refino da granulação) ou de estado sólido (formação de martensita), têm-se a expectativa de melhora nas propriedades voltadas ao desempenho à fadiga.

Dentre as diferentes formas de promover a fusão superficial, pode-se destacar o uso do arco elétrico. Desde que protegido por uma atmosfera inerte e por meio do controle adequado dos parâmetros empregados em soldagem, é possível a obtenção de um tratamento superficial similar a um depósito de solda, porém, sem a necessidade de utilização de um metal de adição [3].

Baseado nesta teoria, o uso da tocha empregada na soldagem plasma, constitui uma alternativa interessante. Devido às características intrínsecas deste processo, o mesmo possibilita a refusão de forma eficiente permitindo ainda o uso de variações (ex. corrente pulsada) que possam resultar em melhorias frente ao desempenho à fadiga.

Com relação aos componentes que falham por fadiga, os rotores de turbinas hidráulicas de geradores elétricos, fabricados 
Tabela 1. Composição química do material base utilizado para obtenção da superfície refundida - \% em peso.*

\begin{tabular}{|c|c|c|c|c|c|c|c|c|c|c|c|}
\hline $\mathrm{C}$ & $\mathrm{Si}$ & $\mathrm{Mn}$ & $\mathrm{Cr}$ & $\mathrm{Ni}$ & $\mathrm{Mo}$ & $\mathrm{Cu}$ & $\mathrm{V}$ & $\mathrm{Ti}$ & $\mathrm{Nb}$ & $\mathrm{P}$ & $\mathrm{S}$ \\
\hline 0,011 & 0,47 & 0,99 & 13,02 & 4,19 & 0,36 & 0,04 & 0,024 & 0,03 & 0,007 & 0,026 & 0,016 \\
\hline
\end{tabular}

$\backslash \mathrm{s} *$ valores fornecidos pelo fabricante do material.

Tabela 2. Parâmetros de soldagem utilizados para refusão superficial.

\begin{tabular}{|l|c|c|c|c|c|c|c|}
\hline \multicolumn{1}{|c|}{ Condição } & $\operatorname{Ip}(\mathrm{A})$ & $\operatorname{Ib}(\mathrm{A})$ & $\operatorname{Im}(\mathrm{A})$ & $\operatorname{Tp}(\mathrm{s})$ & $T b(\mathrm{~s})$ & Tensão $(\mathrm{V})$ & Frequência Hz \\
\hline 1 - Convencional & - & - & 140 & - & - & 23 & - \\
\hline 2 - Pulsado A & 200 & 80 & 140 & 0,1 & 0,1 & 21 a 25 & 5 \\
\hline
\end{tabular}

Ip, corrente de pico; Ib, corrente de base; Im, corrente média; Tp, tempo de pico; $T b$, tempo de base

em aços inoxidáveis martensíticos macios, tem exigido esforços na melhoria de desempenho de forma a evitar a indisponibilidade dos mesmos comprometendo o suprimento de energia [4].

Nestes rotores, além da ocorrência de trincas por fadiga em regiões altamente tensionadas, ocorre o desgaste pela ação de cavitação sendo necessário em ambos os casos efetuar reparos de soldagem. Tais reparos exigem procedimentos de soldagem que garantam a integridade estrutural e resultem em baixo nível tensão residual. Tais características nem sempre são alcançadas haja vista a soldabilidade dos aços inoxidáveis martensíticos envolverem alterações microestruturais que dificultam em alcançar os objetivos necessários [4].

Por outro lado, a alta temperabilidade deste tipo de material, permite que após refusão seja desenvolvida após resfriamento estrutura martensítica a qual, em princípio, resulta em melhor desempenho à fadiga.

Neste sentido, este trabalho teve com o objetivo avaliar o efeito da refusão sobre um aço inoxidável martensítico utilizado na fabricação de rotores de turbinas hidráulicas de forma a implementar tal procedimento ampliando assim a resistência à fadiga quando da utilização destes componentes na geração de energia.

\section{Materiais e métodos}

Na sequência serão descritos os procedimentos utilizados a fim de avaliar o efeito da refusão obtida com tocha plasma nas condições pulsada e convencional envolvendo um aço inoxidável martensítico macio (AIMM). Para tal foram efetuadas análises e ensaios envolvendo caracterização microestrutural e ensaios de fadiga sob flexão em quatro pontos.

\subsection{Material utilizado}

A Tabela 1 apresenta respectivamente a composição química do material base utilizado para a execução da refusão superficial. Tal material base foi fornecido na condição temperada e revenida com dureza de 295 HV0,3 após fundição em molde de areia.

\subsection{Condições de refusão}

As condições de refusão adotadas são apresentadas na Tabela 2. A mesmas foram realizadas com tocha plasma nas condições de corrente contínua e polaridade direta (CC-). Foram efetuadas refusões nas condições de corrente convencional e pulsada, sendo esta última realizada com frequência de $5 \mathrm{~Hz}$. A escolha desta frequência foi baseada nos trabalhos Sundaresan et al [5] Koteswara et al [6], os quais obtiveram redução do tamanho de grão e no trabalho de Henke, [7] o qual obteve um bandeamento de ferrita delta ao longo do cordão da solda. A sobreposição foi de aproximadamente 20 \%. Demais parâmetros foram baseados em testes preliminares de forma a obter maior estabilidade de arco e qualidade de cordão.

As refusões foram realizadas de forma automatizada utilizando-se uma fonte de soldagem multiprocesso e uma tocha plasma refrigerada. A velocidade de deslocamento da tocha plasma foi de $100 \mathrm{~mm} / \mathrm{min}$. Como gás de plasma e de proteção foi utilizado argônio nas vazões de 1.0 e 11 1/min respectivamente. Um eletrodo de tungstênio-toriado tipo EWTh-2 foi utilizado com recuo de $0,8 \mathrm{~mm}$ do bocal da tocha e ângulo de afiação de $60^{\circ}$. A distância bocal-peça foi de $10 \mathrm{~mm}$.

\subsection{Ensaios de fadiga}

Os ensaios de fadiga foram realizados em corpos de prova submetidos a esforço cíclico por flexão em quatro pontos (Figura 1) sendo utilizada máquina de ensaios com acionamento servohidráulico.

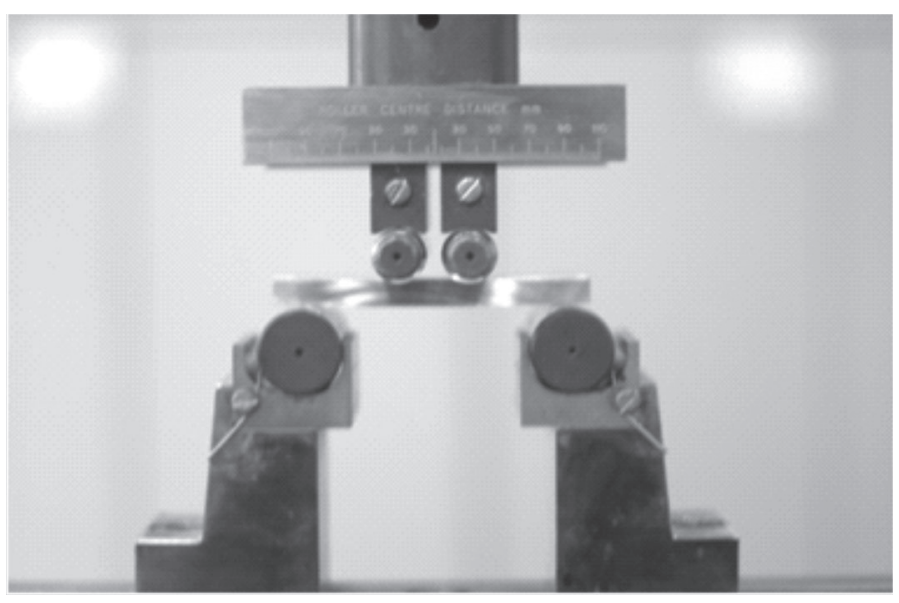

Figura 1. Dispositivo para ensaio de fadiga por flexão em quatro pontos. 
Os corpos de prova para ensaio de fadiga foram obtidos a partir das refusões realizadas em placas de aço AIMM fundido medindo 120x100x10 mm conforme condições da Tabela 2. A Figura 2 ilustra a refusão ao longo de uma placa e a localização da retirada dos corpos de prova sobre a mesma.

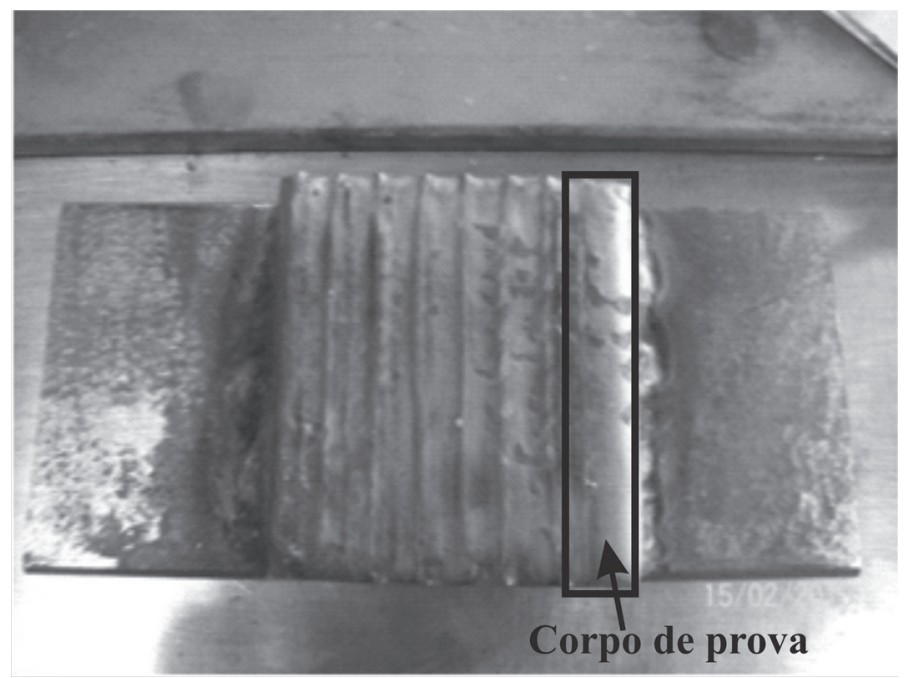

Figura 2. Refusão obtida sobre a placa e o esquema representando posicionamento para retirada de corpos de prova longitudinais ao cordão para o ensaio de fadiga.

As dimensões dos corpos de prova foram aproximadamente 100x10x8 mm sendo a superfície refundida submetida aos esforços cíclicos. A retirada foi efetuada por meio de operação de corte mecânico sendo a superfície refundida lixada e polida em alumina com $1 \mathrm{~mm}$. De forma comparativa foram efetuados ensaios de fadiga em corpos sem refusão, ou seja, sobre o material base como fornecido.

A frequência de carregamento utilizada foi de $20 \mathrm{~Hz}$ e fator $\mathrm{R}$ igual a 0,1 onde $\mathrm{R}$ é igual a smin/smax ou seja tensão mínima sobre a tensão máxima. As tensões máximas aplicadas para os corpos de prova foram de 750, 850 e $1000 \mathrm{MPa}$ sendo estas calculadas conforme equação (1).

smáx. $=3 P(L-t) /\left(w h^{2}\right)$

Onde:

- $\mathrm{P}=$ força aplicada por um dos roletes centrais;

- $\mathrm{L}=$ distância entre os roletes da base $(80 \mathrm{~mm})$;

- $\mathrm{t}$ = distância entre os roletes de aplicação de força $(20 \mathrm{~mm})$;

- $\mathrm{w}=$ largura do corpo de prova;

- $\mathrm{h}=$ espessura do corpo de prova.

Os resultados obtidos foram representados em um gráfico tensão máxima x número de ciclos para ocorrência de falha em escala linear. Foi considerada vida infinita de fadiga o corpo de prova que suportasse um milhão de ciclos. Depois de ensaiados, os corpos de prova foram avaliados via análise metalográfica, especificamente na superfície polida, a fim de serem obtidas informações a respeito do ponto de nucleação da fratura. Em complemento à análise metalográfica, foram efetuadas medidas de microdureza Vickers com $300 \mathrm{~g}$ de carga ao longo das superfícies refundidas e também do material base. As medidas foram realizadas longitudinalmente sendo indicado o valor médio obtido após obtenção de três perfis de microdureza.

\section{Resultados e discussões}

A Figura 3 e a Tabela 3 apresentam os resultados dos ensaios de fadiga obtidos nas condições com refusão convencional, refusão pulsada e ainda no material base sem refusão. Com base nos resultados, constata-se inicialmente que o material refundido apresenta na média uma resistência à fadiga pouco superior em relação ao material sem refusão. Por exemplo, para uma tensão de $850 \mathrm{MPa}$, o número de ciclos para a fratura no material base situa-se em média próximo a 126.000 ciclos enquanto que para o material refundido este valor estaria em aproximadamente 188.000 ciclos. Destaca-se ainda a ocorrência de sobreposição total dos resultados entre as condições com refusão para os três níveis de tensão bem como entre estas e o material base a 1000 MPa e sobreposição parcial para as condições com refusão e material base nas tensões de 850 e $700 \mathrm{MPa}$.

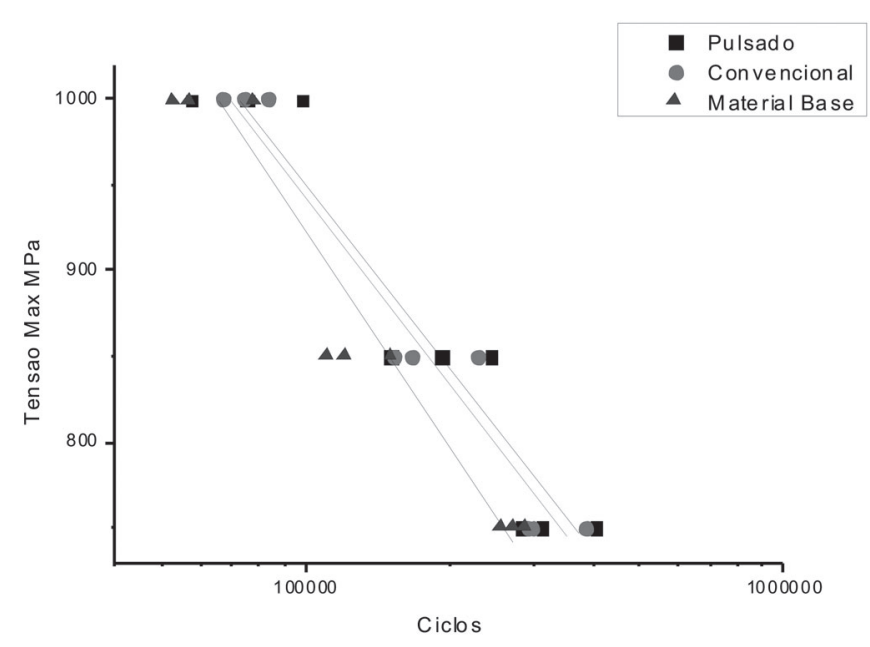

Figura 3. Diagrama Tensão x Número de ciclos obtido nos ensaios de fadiga.

Tabela3. Média dos ciclos de fadiga bem como desvio padrão (SD) obtidos para as condições de refusão e material base conforme tensões utilizadas.

\begin{tabular}{|c|c|c|c|c|c|c|}
\hline Tensão & \multicolumn{2}{|c|}{ Pulsado } & \multicolumn{2}{c|}{ Convencional } & \multicolumn{2}{c|}{ Material Base } \\
\hline $\mathrm{MPa}$ & Média & SD & Média & SD & Média & SD \\
\hline 750 & 332.333 & 63.011 & 324.791 & 50.534 & 270.491 & 16.117 \\
\hline 850 & 195.159 & 46.792 & 182.198 & 39.878 & 126.862 & 20.583 \\
\hline 1000 & 76.859 & 20.361 & 74.648 & 7.856 & 62.266 & 13.412 \\
\hline
\end{tabular}

A pouca diferença de desempenho em favor do material refundido estaria associada, em parte, à presença de tensões residuais compressivas decorrentes da transformação martensítica [8-11] após solidificação e resfriamento as quais minimizam as tensões na superfície impostas durante o ensaio. Este desempenho também foi observado no trabalho 
de Heitkemper et al, [12] ao realizar tratamento térmico com LASER em aços inoxidáveis martensíticos para ferramentas.

Observa-se ainda que o desempenho à fadiga para as superfícies refundidas foi levemente superior ao material base para os níveis de tensão de 850 e $750 \mathrm{MPa}$ e praticamente o mesmo para a tensão de $1000 \mathrm{MPa}$. Este comportamento estaria relacionado ao fato das tensões compressivas minimizarem a ampliação das tensões junto às imperfeições microestruturais, ou seja, para a tensão de $1000 \mathrm{MPa}$ a tensão compressiva existente seria pouco efetiva em inibir a nucleação da trincas nas extremidades dos defeitos. Medidas de microdureza realizadas nas superfícies refundidas revelaram valores médios de $350 \mathrm{HV}$, ou seja, superiores ao material base como fornecido comprovando a ocorrência da formação de martensita após refusão (Figura 4).

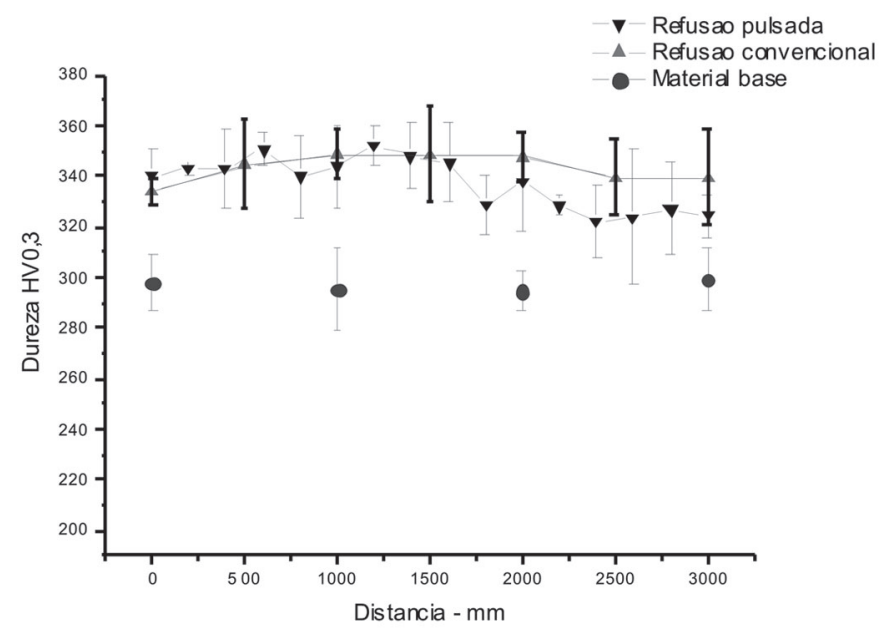

Figura 4. Medidas de microdureza realizadas nas superfícies refundidas e material base.

A análise metalográfica realizada na seção transversal de um dos corpos de prova refundidos revela que a profundidade média de refusão atingiu aproximadamente dois milímetros (Figura 5).

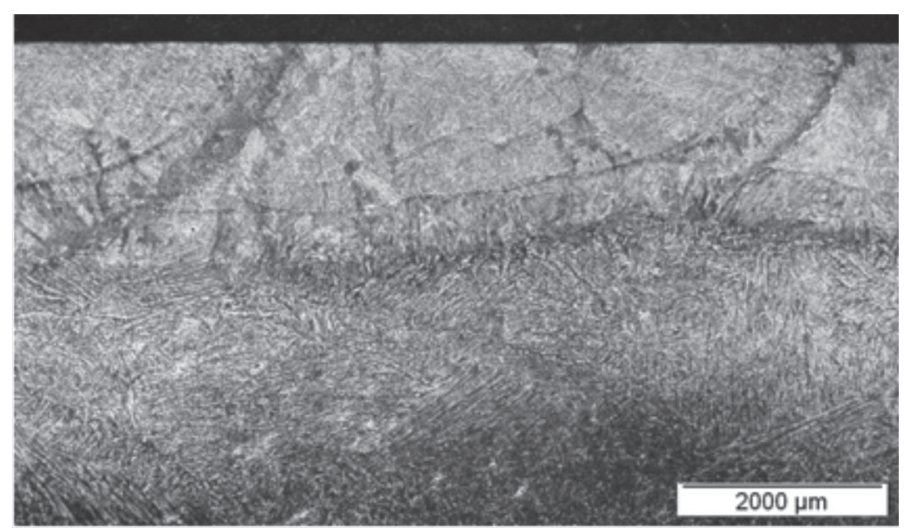

Figura 5. Seção transversal revelando profundidade de refusão.

Com relação à análise metalográfica realizada na superfície dos corpos de prova sem tratamento de refusão, a mesma revelou que a nucleação das trincas ocorre principalmente em defeitos provenientes do processo de fundição, especificamente microrechupes (Figura 6), mesmo sendo a presença destes inferior a $1 \%$ do total da superfície ensaiada. A mesma análise quando efetuada nos corpos de prova refundidos não identificou a presença de tais defeitos com tamanho avantajado o que permite afirmar que a refusão é uma forma eficiente de redução volumétrica destas descontinuidades. Heitkemper et al. [12] ao executarem ensaios de fadiga em um aço inoxidável martensítico estimaram com base na mecânica da fratura linear elástica que o valor crítico de defeito para a nucleação de trincas neste tipo de aço situa-se entre 8 e $30 \mathrm{~mm}$. Os valores de tamanho de defeitos encontrados no material base corrobora tal estimativa.

Como previsto por Meyer et al. [13] foram identificadas, porém em menor número, trincas nucleadas paralelamente às ripas (laths) de martensita com uma inclinação aproximada de $45^{\circ}$ entre a trinca e sentido de aplicação do esforço (Figura 7). Supõe-se que haja certa prevalência da formação de trincas junto aos microrechupes em relação às ripas de martensita.

Com relação aos desempenhos obtidos com a refusão convencional e a refusão pulsada, pode-se constatar que estes resultaram de forma semelhante. A análise metalográfica de ambos os processos resultou em microestrutura constituída de martensita, rede de ferrita delta e inclusões globulares (Figura 8).

A refusão pulsada promoveu a formação de ferrita delta na forma de bandas (Figura 9). Destaca-se que a formação de tal bandeamento foi induzida propositalmente utilizando baixa frequência de forma que se pudesse avaliar uma possível influência deste bandeamento na nucleação de trincas por fadiga. A utilização ou não desta frequência na prática estaria condicionada às necessidades de soldagem de determinado componente. Além da pulsação, foi constatado que a sobreposição também resultava na formação de regiões contínuas de ferrita delta.

Após serem ensaiadas por fadiga a análise metalográfica revelou que a nucleação de trincas no interior destas regiões (Figuras 10 e 11). A nucleação de trincas em regiões contendo ferrita delta também foi constatada em corpos de prova sem pulsação. Rho et al. [14] ao estudarem o efeito da ferrita delta na ocorrência de trincas em aços inoxidáveis $304 \mathrm{~L}$, constataram que a interface desta fase com a matriz austenítica atuava como agente de nucleação de trincas. Destaca-se, porém, que apesar do material estudado por Rho tratar-se de um aço inoxidável com matriz austenítica contendo veios de ferrita alinhados, considera-se, a princípio, que a presença da ferrita teria um efeito similar em promover a nucleação de trincas por fadiga mesmo em se tratando de um material com matriz martensítica.

Acredita-se que haja um efeito sinérgico entre a presença de ferrita delta e as ripas de martensita a $45^{\circ}$ o qual favoreça a nucleação das trincas junto a estas regiões. 


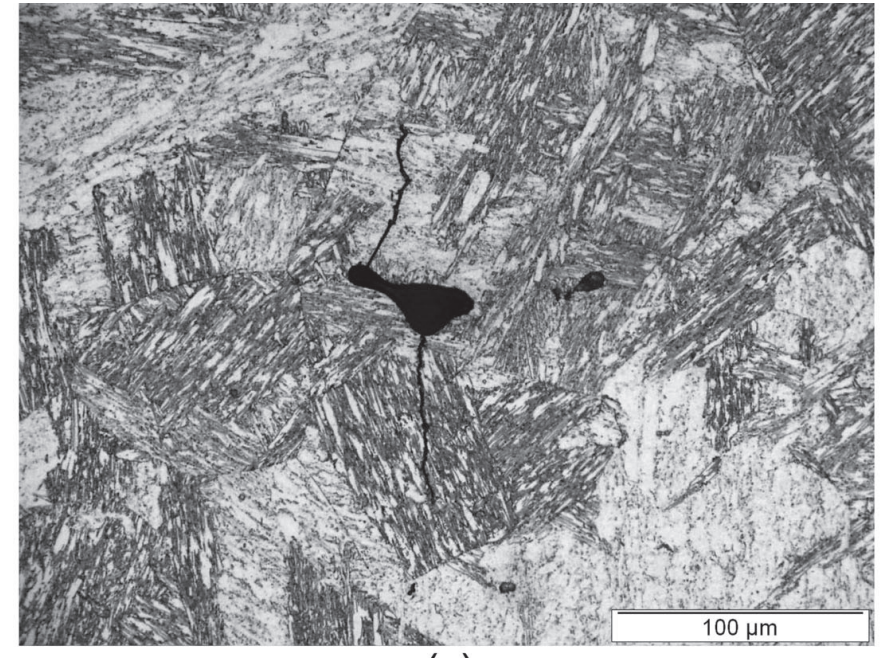

(a)

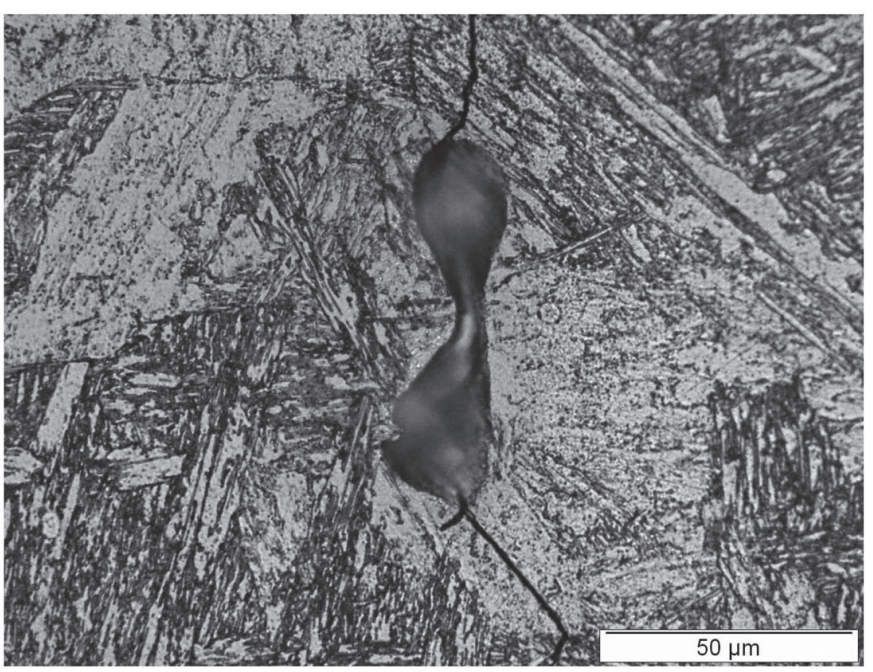

(c)

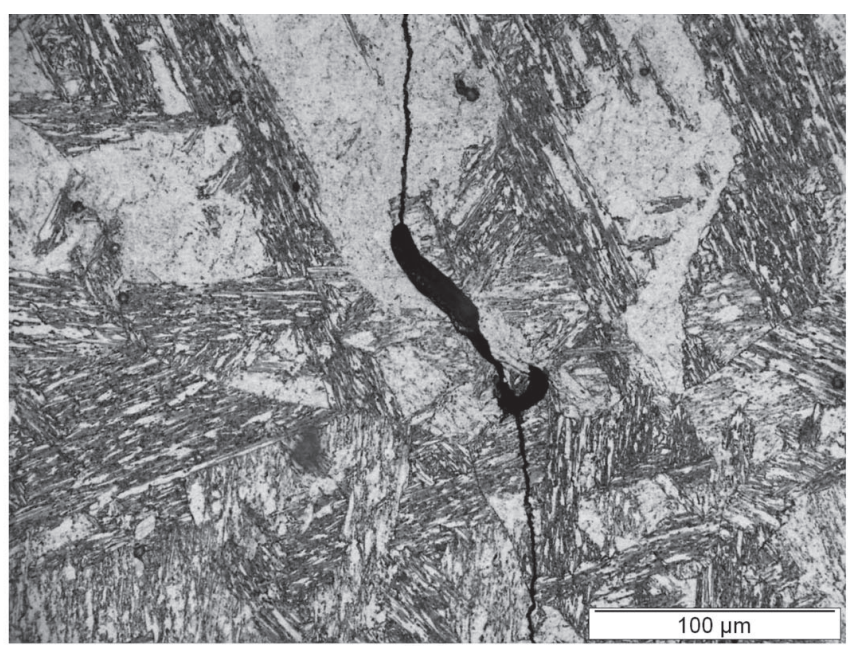

(b)

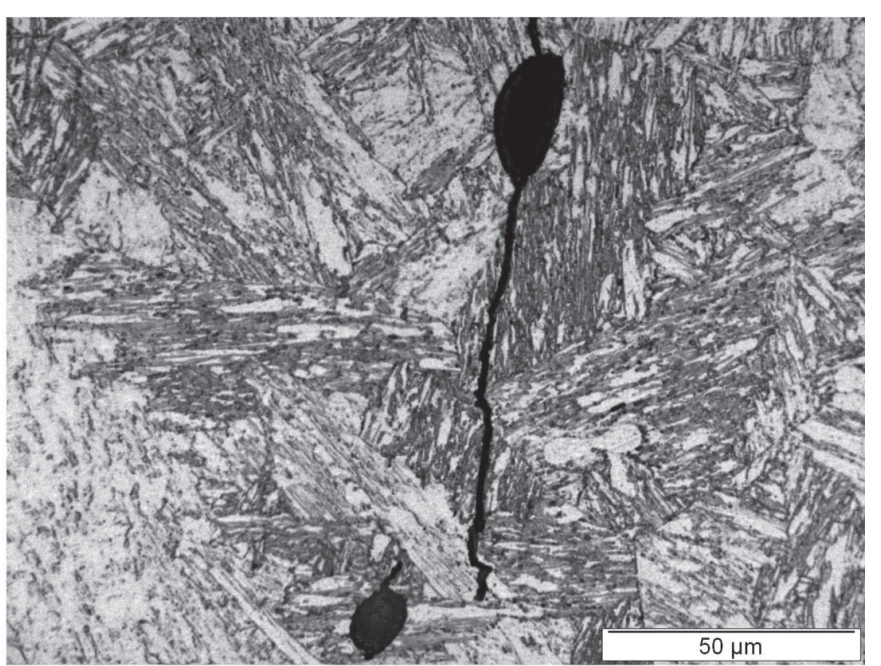

(d)

Figura 6. Descontinuidades encontradas no Material Base na forma de microrechupes revelando a nucleação de trincas sobre as mesmas após ensaio de fadiga. Ataque: Vilella. Direção de carregamento

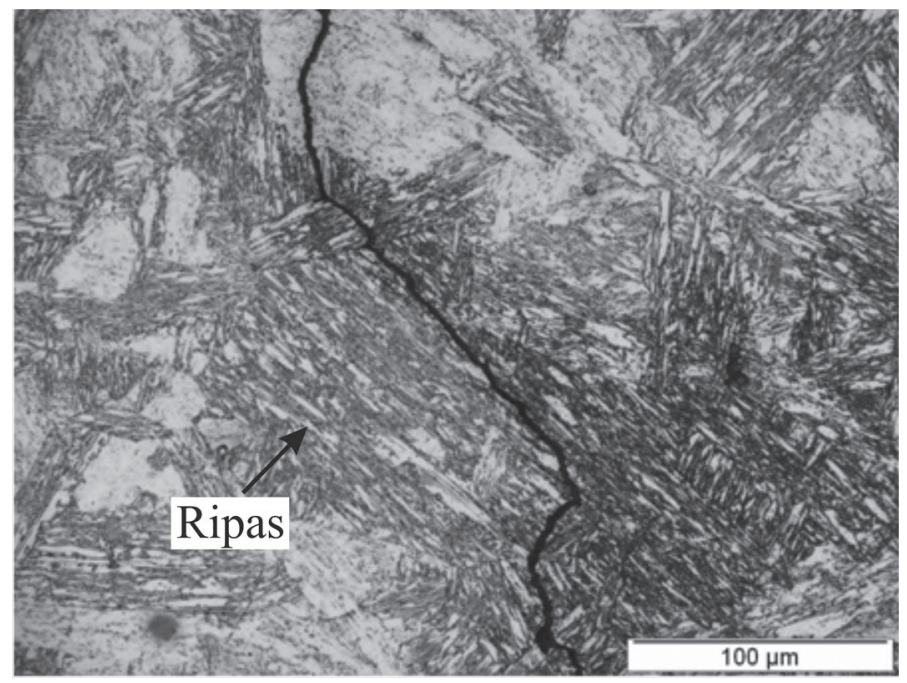

Figura 7. Trinca com nucleação junto às ripas de martensita. Ataque: Sulfúrico + Vilella. Direção de carregamento

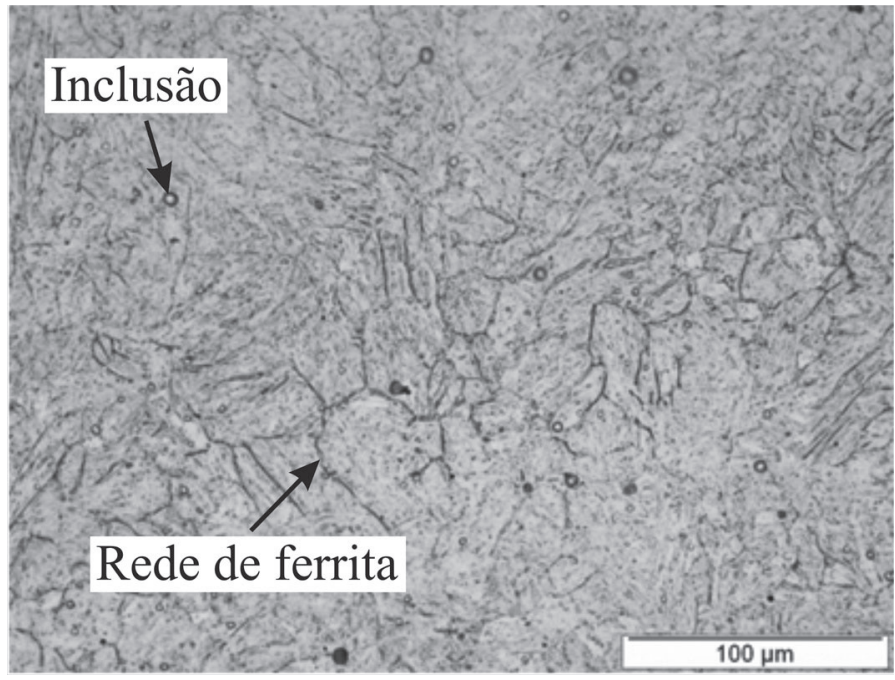

Figura 8. Análise metalográfica da superfície refundida revelando rede de ferrita delta, inclusões e matriz martensítica. Ataque: Sulfúrico e Vilella. 


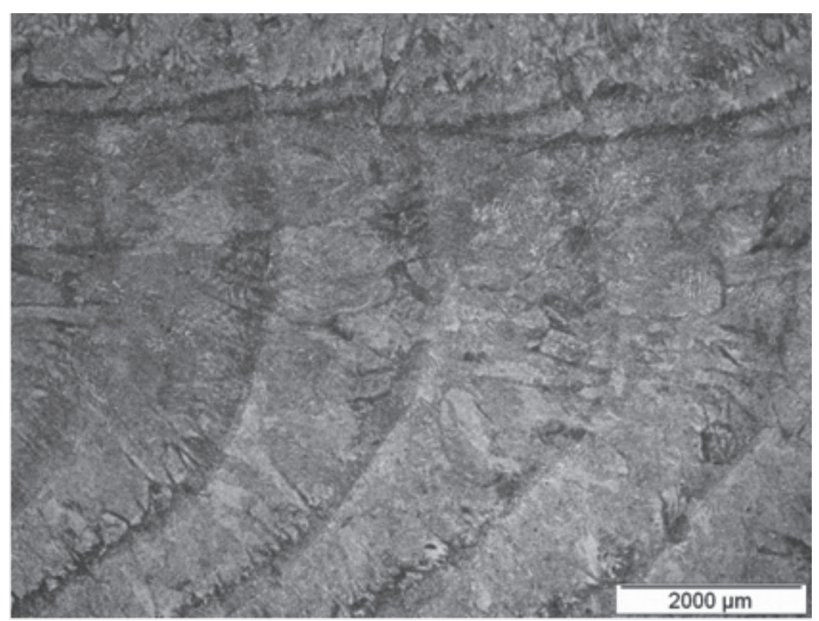

Figura 9. Análise metalográfica da superfície refundida com pulsação de corrente revelando bandas de ferrita delta (áreas escuras). Ataque: Sulfúrico e Vilella.

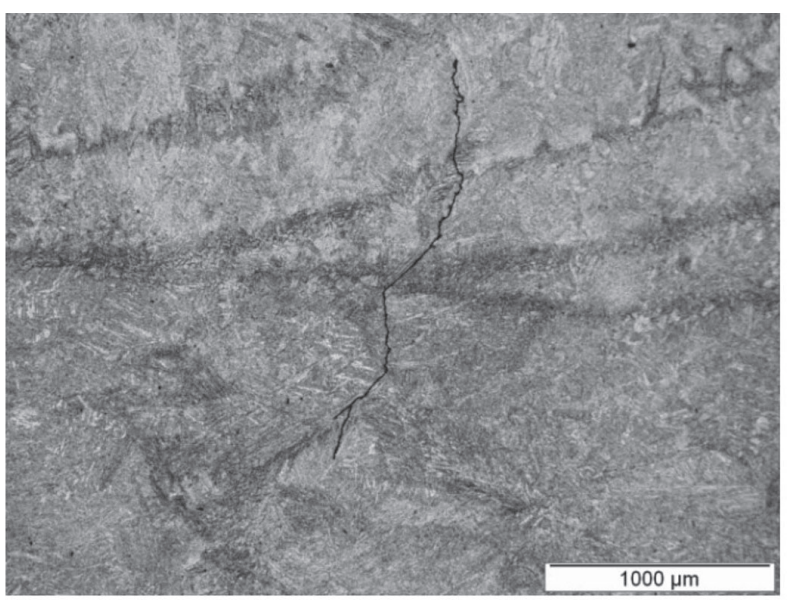

(a)

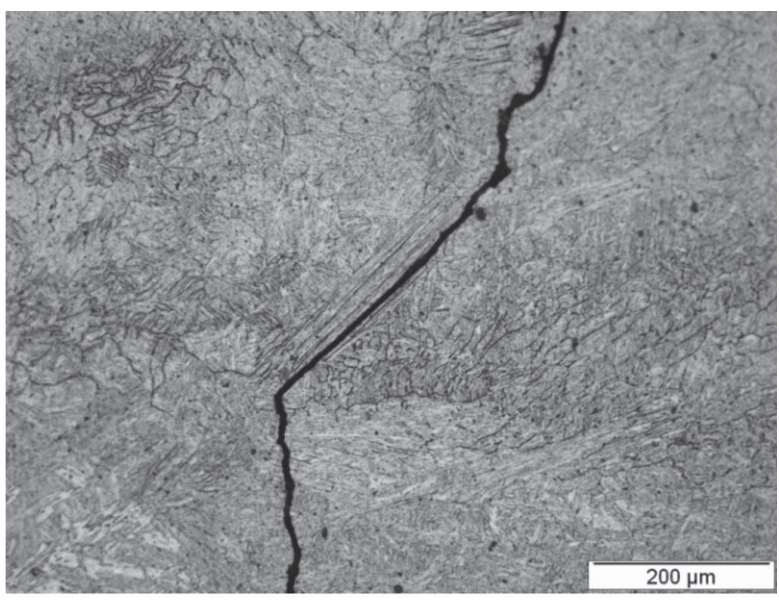

(b)

Figura 10. Em (a) Análise metalográfica da superfície refundida com pulsação de corrente revelando trinca posicionada no interior das bandas de ferrita delta (áreas escuras). Em (b) Detalhe de (a).Ataque: Sulfúrico e Vilella. Direção de carregamento

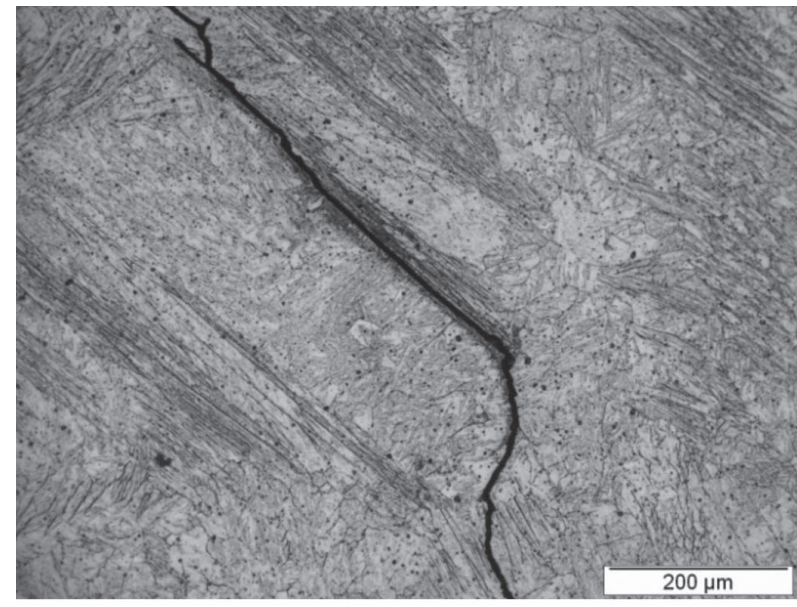

(a)

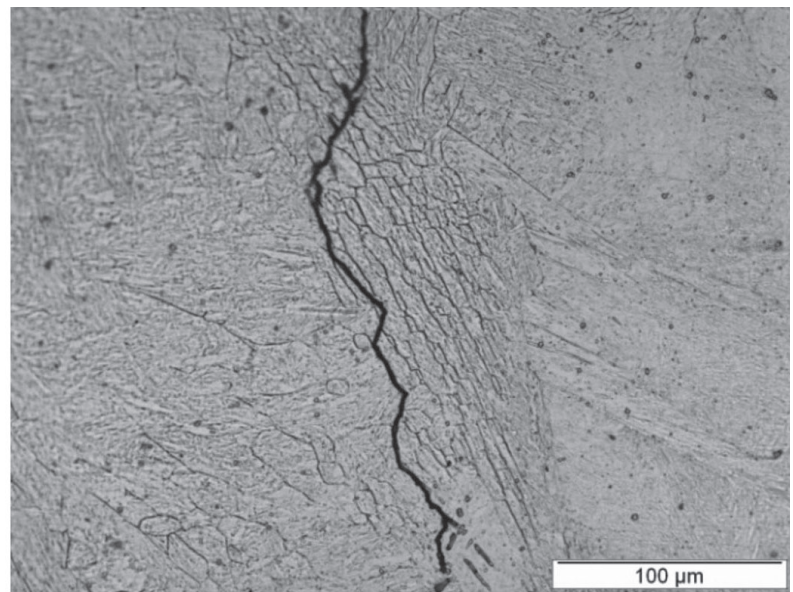

(b)

Figura 11. Exemplos de nucleação de trincas junto à ferrita delta em (a) e em (b). Ataque: sulfúrico. Direção de carregamento: 


\section{Conclusões}

Com base no estudo realizado é possível destacar o seguinte:

- O tratamento de refusão superficial produzido por tocha plasma resultou em média uma vida de fadiga pouco superior em comparação ao material sem este tratamento.

- Infere-se que o melhor desempenho promovido pela refusão esteja relacionado à eliminação de microrechupes os quais atuam como agentes nucleantes de trincas e ainda em consequência de tensões residuais compressivas resultantes da transformação martensítica.

- Com relação à obtenção de um incremento na vida de fadiga produzido pelo processo de pulsação frente ao modo convencional, o mesmo foi considerado pouco significativo.

- As análises efetuadas sobre os corpos de prova ensaiados revelaram que a nucleação do processo de fadiga na condição refundida ocorria em regiões contendo ferrita delta em associação à presença de ripas de martensita orientadas a $45^{\circ} \mathrm{em}$ relação à direção de solicitação de esforços.

\section{Agradecimentos}

Ao programa PRH24 da UFPR pelo suporte financeiro a este trabalho e ao Instituto de Tecnologia para o Desenvolvimento - LACTEC pela disponibilização do equipamento de ensaio de fadiga.

\section{Referências Bibliográficas}

[1] FUCHS, H.O.; STEPHENS, R.I.; Metal Fatigue In Engineering, John Wiley \& Sons, New York, 1980.

[2] ASM HANDBOOK, Fatigue and Fracture, Vol. 19, ASM International, Materials Park, OH, 1996.

[3] ORLOWICZ A. W., MRÓZ M.; Microstructure and fatigue strength of A356 alloy castings refined on the surface by rapid crystallization. Zeitschrift fuer Metallkunde/Materials Research and Advanced Techniques

Volume 94, Issue 12, December 2003, Pages 1320-1326.

[4] AKHTAR, A.; BRODIE, N.W. Field welding of large turbine runners. Water Power \& Dam Construction, p40-46, Sep.1979.

[5] SUNDARESAN S., JANAKI RAM G. D., MADHUSUDHAN REDDY G., Microstructural refinement of weld fusion zones in $\alpha-\beta$ titanium alloys using pulsed current welding. Materials Science and Engineering A262, 1999, p88-100.

[6] KOTESWARA RAO, S.R.; MADHUSUDHANA REDDY G., KAMARAJ, M.; PRASAD RAO, K; Grain refinement through arc manipulation techniques in Al-Cu alloy GTA welds. Mat. Science and Engineering A (404) 2005 227-234.

[7] HENKE S. L.; Efeito Da Soldagem Plasma Pulsada Na Microestrutura E Resistência À Fadiga De Um Aço Inoxidável Supermartensítico. Tese, UFPR PgMec. 2010.

[8] THIBAULT D., BOCHERB P., THOMAS M.; Residual stress and microstructure in welds of $13 \% \mathrm{Cr}-4 \% \mathrm{Ni}$ martensitic stainless steel, J.Mater. Process. Tech. (2008).

[9] HWANG J-R. FUNG, C-P.; Effect of electron beam surface hardening on fatigue crack growth rate in
AISI 4340 steel. Surface and Coatings Technology 80 (1996) 271-278.

[10] LINGAMANAIK S. N., CHEN, B. K.; Thermo-mechanical modelling of residual stresses induced by martensitic phase transformation and cooling during quenching of railway wheels. Journal of Materials Processing Technology 211 (2011) 15471552 .

[11] THIBAULT D., BOCHERB P., THOMAS M., GHARGHOURIC M., CÔTÉB M. Residual stress characterization in low transformation temperature $13 \% \mathrm{Cr}-4 \% \mathrm{Ni}$ stainless steel weld by neutron diffraction and the contour method. Materials Science and Engineering A 527 (2010) 6205-6210.

[12] HEITKEMPER M., BOHNE C., PYZALLA A., FISCHER A.; Fatigue and fracture behaviour of a laser surface heat treated martensitic high-nitrogen tool steel. International Journal of Fatigue, 25, 2003, p101-106.

[13] MEYER, S.; BRUCKNER-FOIT, A. MOSLANG, A.; A stochastic simulation model for microcrack initiation in a martensitic steel. Computational Materials Science 26 (2003) 102110.

[14] RHO, S. B., HONG, H. U., NAM, S.W., The effect of deltaferrite on fatigue cracks in 304L steels. International Journal of Fatigue. 22, 2000, p683-690. 